\title{
Influence of chlorine substitution on adsorption of gaseous chlorinated phenolics on multi-walled carbon nanotubes embedded in $\mathrm{SiO}_{2}$
}

\author{
S. Tulaphol ${ }^{1}$-S. Bunsan ${ }^{2}$ - E. Kanchanatip ${ }^{3}$ - H.-Y. Miao ${ }^{4}$ N. Grisdanurak ${ }^{1,5}$ • \\ W. Den ${ }^{6}$
}

Received: 19 November 2015/Revised: 15 March 2016/Accepted: 15 March 2016/Published online: 25 April 2016

(C) Islamic Azad University (IAU) 2016

\begin{abstract}
Multi-walled carbon nanotubes (MWCNTs) embedded in $\mathrm{SiO}_{2}$ particles were prepared through the floating-catalyst chemical vapor deposition method. The parameters reaction time and flow rate of the carbon source $\left(\mathrm{CH}_{4}\right)$ were studied to obtain optimum conditions for MWCNT synthesis. The obtained MWCNTs were characterized by transmission electron microscopy, scanning electron microscopy, Raman spectroscopy, and Fourier transform infrared spectroscopy to confirm their morphology and crystallinity. The optimum conditions were a $\mathrm{CH}_{4}$ flow rate of $100 \mathrm{ml} / \mathrm{min}$ in a $\mathrm{H}_{2}-\mathrm{Ar}$ mixture at a flow rate of $500 \mathrm{ml} / \mathrm{min}$ and a reaction time of $20 \mathrm{~min}$. Under these conditions, MWCNTs with average outer and inner diameters of around 50 and $10 \mathrm{~nm}$, respectively, were obtained. $\mathrm{SiO}_{2}$ particles with embedded MWCNTs were studied for
\end{abstract}

W. Den

wden@thu.edu.tw

1 Department of Chemical Engineering, Faculty of Engineering, Thammasat University, Pathumthani 12120, Thailand

2 Science Park Promotion Agency, Ministry of Science and Technology, Bangkok 10330, Thailand

3 International Postgraduate Program in Environmental Management, Chulalongkorn University, Bangkok 10330, Thailand

4 Department of Electrical Engineering, Tunghai University, No. 1727, Sec. 4, Taiwan Boulevard, Taichung 40704, Taiwan, ROC

5 Center of Excellence in Environmental Catalysis and Adsorption, Thammasat University, Pathumthani 12120, Thailand

6 Department of Environmental Science and Engineering, Tunghai University, No. 1727, Sec. 4, Taiwan Boulevard, Taichung 40704, Taiwan, ROC their adsorption of gaseous chlorinated phenolic compounds (CPCs), with emphasis on the effect of number of chlorine substituents. The CPC compounds of 2-chlorophenol (CP) and 2,4-dichlorophenol (DCP) were compared against phenol (P). Adsorption of $\mathrm{P}$ and CPCs on the particles fit well the Langmuir isotherm. The adsorption capacities of $\mathrm{P}, \mathrm{CP}$, and $\mathrm{DCP}$ on $\mathrm{SiO}_{2}$ particles with embedded MWCNTs were found to be 3.12, 13.83, and $44.25 \mathrm{mg} / \mathrm{g}$, respectively. Desorption activation energy was determined by thermogravimetric analysis. Chlorine substitution on $\mathrm{P}$ changed the adsorption process from physical to chemical adsorption. The particles showed high potential for use as a pre-concentration unit for solid-phase microextraction.

Keywords Multi-walled carbon nanotubes · Phenolic compounds · Adsorption

\section{Introduction}

Carbon nanotubes (CNTs) are among the best adsorbents for volatile organic compounds (VOCs) because of their uniform porosity, as well as high thermal stability and high chemical stability, which, in general, lead to their high adsorptive capacity. Chlorinated phenolic compounds (CPCs), in particular, which are not readily biodegradable and therefore potentially toxic to microorganisms and to humans at low concentrations, can be removed by adsorption on CNTs. This approach, particularly for aqueous-phase treatment, has been widely studied (Gupta et al. 2012, 2013; Lin and Xing 2008; Salam et al. 2010). However, adsorption processes using CNTs inevitably cause bundling of CNTs, which can adversely affect gas permeation and molecular diffusion in such processes 
(Chen et al. 2009). This characteristic of CNTs is a crucial factor that limits their adsorption performance. To overcome these drawbacks, multi-walled carbon nanotubes (MWCNTs) have been directly grown on $\mathrm{SiO}_{2}$ particles. He et al. (2010) proved that the floating-catalyst chemical vapor deposition (FCCVD) technique can yield uniformly distributed CNTs on the $\mathrm{SiO}_{2}$ surface, thereby reducing the chance of CNT aggregation. However, studies on gaseousphase treatment of CPCs over CNTs are few.

Polychlorinated $p$-dioxins (PCDDs) and polychlorinated furans (PCDFs) have been identified as persistent toxic substances in the environment. These chemical groups are generally released from incineration systems. They form by rearrangement of chlorine atoms on CPCs in the postcombustion region of incinerators (Bunsan et al. 2013). The United States Environmental Protection Agency has listed PCDDs and PCDFs as priority pollutants because of their extreme toxicity and because of their hazardous classification as human carcinogens and mutagens (US EPA 2000).

To reduce the concentration of PCDDs and PCDFs before their release into the atmosphere, adsorption processes may be utilized. However, direct capture using CNTs in the incinerator is impractical. Alternatively, CNTs may be used in analytical quantification of trace concentrations of gaseous PCDDs and PCDFs via solid-phase microextraction (SPME), which requires a pre-concentration unit.

In order to use CNTs in SPME, the affinity of the adsorbates (CPCs) for the adsorbent (CNTs) should be considered as the primary step (Ali 2012; Gupta et al. 2011b). For activated carbon derived from Jatropha curcas seeds, for example, adsorption capacities for chlorinated volatile hydrocarbons are affected significantly by the number of chlorine atoms and the chemical polarities of these hydrocarbons (Hsu et al. 2014). To our knowledge, only a few studies on the adsorption of gaseous CPC on CNTs have been reported (Agnihotri et al. 2005; Shih and Li 2008). These reports do not mention the effect of the chlorine substituents. On the other hand, the adsorption characteristics of volatile VOCs on CNT-based materials have been reported. Crespo and Yang (2006) performed adsorption experiments on VOCs $\left(\mathrm{C}_{4} \mathrm{H}_{4} \mathrm{~S}, \mathrm{C}_{6} \mathrm{H}_{6}\right.$, and $\mathrm{C}_{6} \mathrm{H}_{12}$ ) using SWCNTs. Their results show that the adsorption behaviors of these VOCs on SWCNTs may be described according to their bundle morphologies by both the Langmuir and Freundlich isotherms. The adsorption behavior also depends on the properties of the adsorbate itself, which mainly adsorbs as a monolayer (Long and Yang 2001).

The aim of this study was to examine the characteristics CPC adsorption onto MWCNTs embedded in $\mathrm{SiO}_{2}$ particles that were synthesized in this work. Optimal conditions for the synthesis of MWCNTs were investigated, and the morphologies of the MWCNTs were characterized. Gaseous adsorption experiments at equilibrium were conducted. Adsorption behaviors were characterized by their activation energies of desorption $\left(E_{\mathrm{d}}\right)$, which were determined by TGA-DTG. Data from batch experiments were evaluated to establish the best-fitting adsorption isotherm models.

\section{Materials and methods}

\section{Synthesis of MWCNTs embedded in $\mathrm{SiO}_{2}$}

MWCNTs were synthesized through the FCCVD technique under atmospheric pressure. A schematic diagram of the synthetic setup is shown in Fig. 1. The system consists of a gas-controlling unit and a downstream mixing system. High-purity $(>99 \%)$ gases $\left(\mathrm{H}_{2}, \mathrm{Ar}\right.$, and $\left.\mathrm{CH}_{4}\right)$ were used in the synthesis. A mixture of $\mathrm{H}_{2}, \mathrm{Ar}$, and $\mathrm{CH}_{4}$ was constantly introduced into a quartz tube $(54 \mathrm{~mm}$ ID and $700 \mathrm{~mm}$ length) used for growing the MWCNTs. The flow rates of $\mathrm{H}_{2}$ and Ar were, respectively, fixed at 300 and $200 \mathrm{ml} / \mathrm{min}$ in all experiments.

Prior to synthesis, $1 \mathrm{~g}$ of the floating catalyst, ferrocene, was transferred to a ceramic boat that was then placed in the preheated zone. We used $\mathrm{SiO}_{2}$ particles $(100 \mu \mathrm{m}$ average diameter) as the carrier template because they are stable at high temperature and their size is suitable for packing in the small column used in SPME applications. A predetermined amount of $\mathrm{SiO}_{2}$ particles was sonicated in the solvents of distilled water, ethanol, and acetone for 5 min and subsequently dried overnight at $120{ }^{\circ} \mathrm{C}$ in an oven. Three grams of the obtained $\mathrm{SiO}_{2}$ particles was uniformly distributed on a $\mathrm{SiO}_{2}$ wafer, which was then placed in the reaction zone. Temperatures for the preheating and reaction zones were set at 120 and $800{ }^{\circ} \mathrm{C}$, respectively.

The carbon source in the study, methane $\left(\mathrm{CH}_{4}\right)$, is a key factor for CNT growth. The effect of the flow rate of $\mathrm{CH}_{4}$ on the rate of CNT growth was studied by varying it in the range of $25-300 \mathrm{ml} / \mathrm{min}$. The carbon product, MWCNTs, was collected at five times within 5-40 min of the reaction. Quantification of yield for each run was evaluated on a substrate basis, as presented in Eq. 1.

Yield of carbon product $=\frac{M_{\text {as }- \text { syn }}-M_{\text {calcined }}}{M_{\text {calcined }}}$

where $M_{\text {as-syn }}$ is the weight of the as-synthesized MWCNTs, and $M_{\text {calcined }}$ is the weight after their calcination at $850{ }^{\circ} \mathrm{C}$ for $3 \mathrm{~h}$ or upon reaching a constant value, which ensures that all of the carbon was removed. 
Fig. 1 A schematic diagram of experiment setup for $\mathrm{SiO}_{2}$ particles embedded MWCNTs synthesis

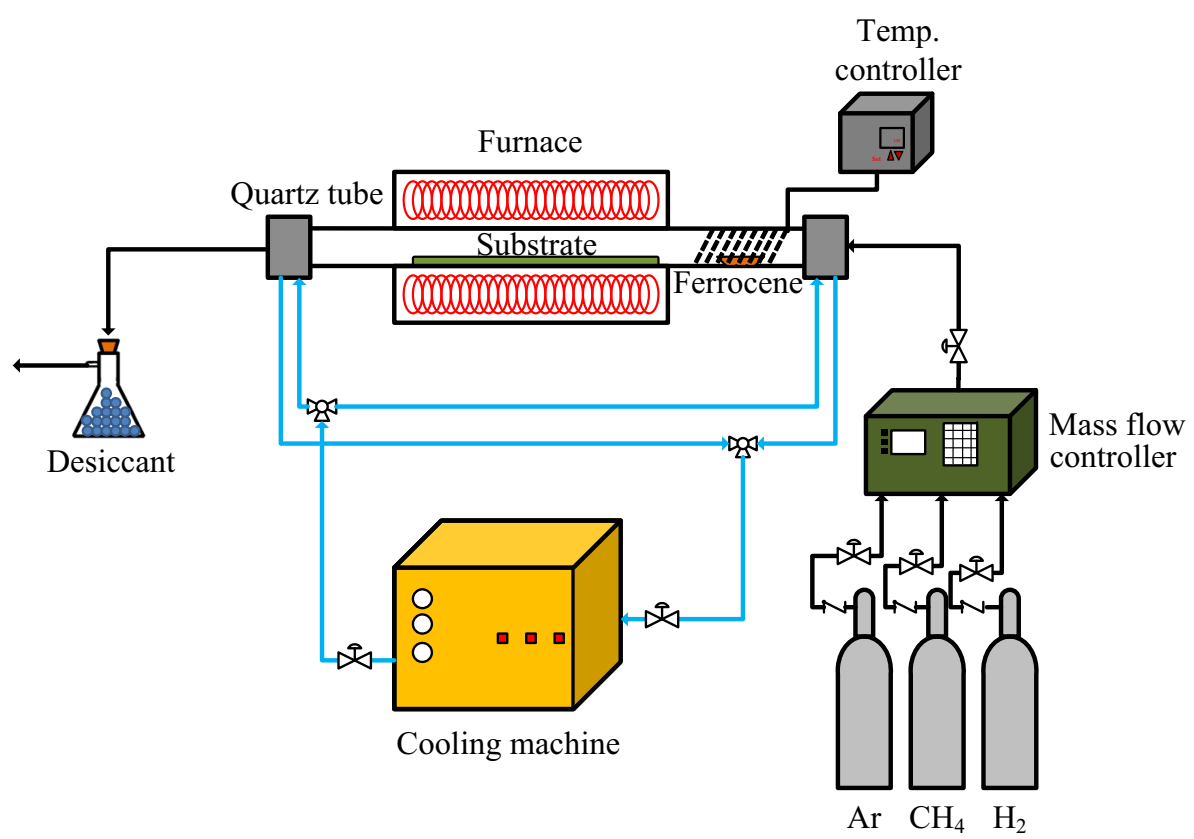

\section{Adsorption tests}

$\mathrm{SiO}_{2}$ particles with embedded MWCNTs were investigated for their capability to adsorb the CPCs phenol (P), 2-chlorophenol (CP), and 2,4-dichlorophenol (DCP). The synthesized adsorbent $(5 \mathrm{mg})$ was transferred to a $55-\mathrm{ml}$ sample container. Prior to the introduction of the CPC gas, the container was purged with $\mathrm{N}_{2}$. Initial concentration of each CPC in the gas phase to $1-500 \mathrm{ppm}$ was performed by controlling by the amount of CPC injected. Adsorption studies were carried out at room temperature $\left(25^{\circ} \mathrm{C}\right)$ to ensure that processes taking place in the gas phase reached equilibrium. The equilibrated gas was then sampled and analyzed by gas chromatography (GC; GC K07380, Thermo Scientific, USA) and mass spectrometry (MS; Trace DSQ II, Thermo Scientific, USA).

GC was performed by using a TG-5MS capillary column (30 m length, $0.25 \mathrm{~mm}$ ID, and $0.25 \mu \mathrm{m}$ nominal film thickness). The carrier gas, helium, was introduced at a flow rate of $1 \mathrm{ml} / \mathrm{min}$, while the split flow was controlled at $10 \mathrm{ml} / \mathrm{min}$. The injection temperature was set at $280{ }^{\circ} \mathrm{C}$. The transferring line between the GC and MS systems was maintained at $250{ }^{\circ} \mathrm{C}$. The operating temperature was programmed as follows: Injection temperature was initially held at $70{ }^{\circ} \mathrm{C}$ for $1 \mathrm{~min}$, ramped at $20^{\circ} \mathrm{C} / \mathrm{min}$ to $110{ }^{\circ} \mathrm{C}$, ramped further at $25{ }^{\circ} \mathrm{C} / \mathrm{min}$ to $200{ }^{\circ} \mathrm{C}$, and then held at this final value for $2 \mathrm{~min}$. An ion source temperature of $200{ }^{\circ} \mathrm{C}$ was used. The MS detector was operated in fullscan electron ionization mode, in which data in the range of $\mathrm{m} / \mathrm{z}$ 50-400 were obtained.

The adsorption behaviors of $\mathrm{CPCs}$ on $\mathrm{SiO}_{2}$ particles with embedded MWCNTs were studied by thermogravimetric technique. Saturated adsorbents were prepared by placing $10 \mathrm{~g}$ of each phenolic compound and $0.2 \mathrm{~g}$ of the adsorbent in a desiccator, which contained $10 \mathrm{~g}$ of molecular sieve (3 $\AA$ ) for capturing moisture. Afterward, the adsorption was carried out for a week under ambient conditions. The saturated adsorbents were then characterized by TGA-DTG (SII Exstar6000, Japan) using different heating rates (1, 3, 5, and $\left.7^{\circ} \mathrm{C} / \mathrm{min}\right)$. The thermograms were examined to determine the $E_{\mathrm{d}}$ for each adsorbed chemical.

\section{Characterizations}

The morphology of the $\mathrm{SiO}_{2}$ particles with embedded MWCNTs was characterized by scanning electron microscopy (SEM; JEOL 6500, Japan) and transmission electron microscopy (TEM; JEOL JSM 7100, Japan). The sample for SEM was coated with platinum by using a JEOL JFC$1100 \mathrm{E}$ ion-sputtering device and then transferred to a JEOL 6500 sample chamber. An accelerating voltage of $15-40 \mathrm{kV}$ was used. The TEM specimen was prepared by depositing the sample onto a copper grid (300 mesh), which was then rapidly transferred to a JEOL JFM 7100 operated at $100 \mathrm{kV}$. Raman spectroscopy and Fourier transform infrared (FTIR) spectroscopy were employed to confirm the characteristics of the carbon materials. Raman spectroscopy using an NT-MTD Raman spectroscope (Ntegra Spectra, Germany) was performed with an Ar laser $(473 \mathrm{~nm})$ for excitation at room temperature to characterize the graphitic ordering of the sample. For FTIR spectroscopy, the sample was ground in an agate mortar and pestle until it had approximately the same consistency as the $\mathrm{KBr}$ powder. $\mathrm{KBr}$ was added and mixed thoroughly 
with the sample, and the powdered mixture was transferred to a sample barrel and then pressed under $10 \mathrm{t}$ for $2 \mathrm{~min}$ before it was placed on a cell. FTIR spectra were recorded in the $400-4000 \mathrm{~cm}^{-1}$ range.

\section{Results and discussion}

MWCNTs were synthesized by using methane as a carbon source. To prevent their aggregation, $\mathrm{SiO}_{2}$ was used as a substrate. Two important factors, the reaction time and amount of carbon source, were studied to determine the optimal conditions for the synthesis.

\section{Synthesis of $\mathrm{SiO}_{2}$ particles with embedded MWCNTs}

The morphologies of the as-synthesized materials obtained under different reaction times $(5,20$, and $40 \mathrm{~min}$ ) were characterized by SEM, the images from which are shown in Fig. 2. The study was carried out at a $\mathrm{CH}_{4}$ flow rate of $100 \mathrm{ml} / \mathrm{min}$. We found that longer reaction times produced a larger amount of MWCNTs. However, the image of MWCNTs obtained at 40-min reaction time shows a nonuniform pattern (Fig. 2c). As the ferrocene catalyst introduced was fixed, the rate of MWCNTs production may be explained by the catalyst deactivation model ( $\mathrm{Yu}$ et al. 2007). The amount of carbon is an important parameter affecting the growth of MWCNTs. Various flow rates of $\mathrm{CH}_{4}(25,50,100,150,200$, and $300 \mathrm{ml} / \mathrm{min})$ were then used for the synthesis of the particles within a reaction time of $20 \mathrm{~min}$. SEM images with a function of the carbon source flow rate show (in Fig. 3) that at low flow rates, an increase in $\mathrm{CH}_{4}$ flow rate is correlated with a higher yield of MWCNTs. However, the yield of MWCNTs decreased when the $\mathrm{CH}_{4}$ flow rate was higher than $100 \mathrm{ml} / \mathrm{min}$. This change implies that the reaction leading to MWCNT formation is limited by its rate. That is, providing the system with excess $\mathrm{CH}_{4}$ does not increase the reaction rate.

In our case, the catalyst was consumed during synthesis. The growth rate of the MWCNTs may be explained by the following assumptions through a differential equation (Eq. 2): (1) The catalyst shows uniform activity, (2) the MWCNT yield is directly proportional to the amount of active catalyst, and (3) the amount of deactivated catalysts is proportional to the amount of active catalysts.

$\frac{\partial Y}{\partial t} \propto \mathrm{e}^{-\frac{t}{\tau_{o}}}$

Integration of Eq. 2 yields an exponential equation,

$Y(t)=r_{0} \tau_{0}\left(1-\mathrm{e}^{-\frac{t}{\tau_{0}}}\right)$
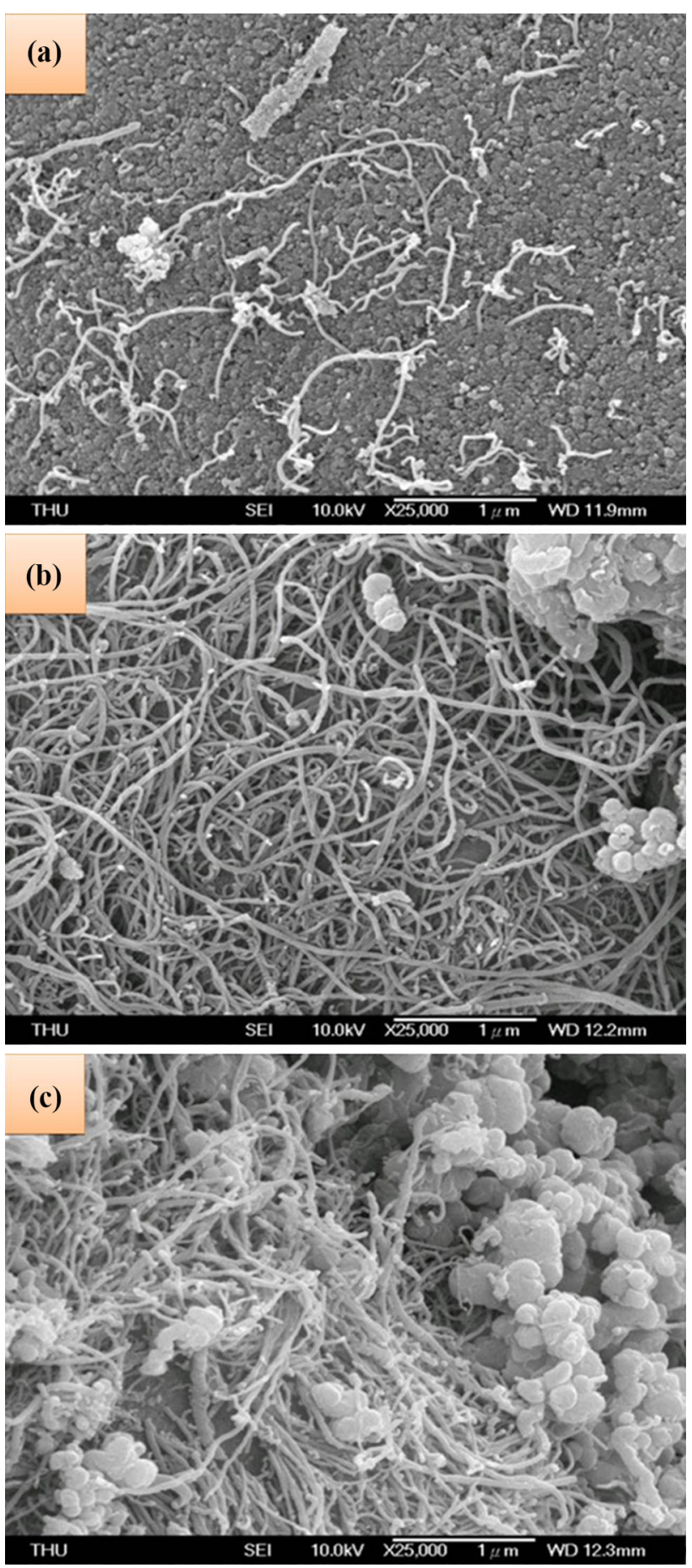

Fig. $2 \mathrm{SEM}$ images of $\mathrm{SiO}_{2}$ particles embedded MWCNTs synthesized at various reaction times: a $5 \mathrm{~min}$, b $20 \mathrm{~min}$, and c $40 \mathrm{~min}$

where $Y(t), r_{0}, \tau_{0}$, and $t$ are the yield of the carbon product as a function of time $\left(\mathrm{mg}_{\mathrm{CNT}} / \mathrm{g}_{\text {subs }}\right)$, the initial growth rate $\left(\mathrm{mg}_{\mathrm{CNT}} /\left(\mathrm{g}_{\text {subs }}-\mathrm{min}\right)\right)$, the catalyst lifetime $(\mathrm{min})$, and the reaction time ( $\mathrm{min}$ ), respectively. Figure 4 shows the yields of the synthesized MWCNTs fitted with a curve (red dashed line), which has a high goodness of fit (correlation 

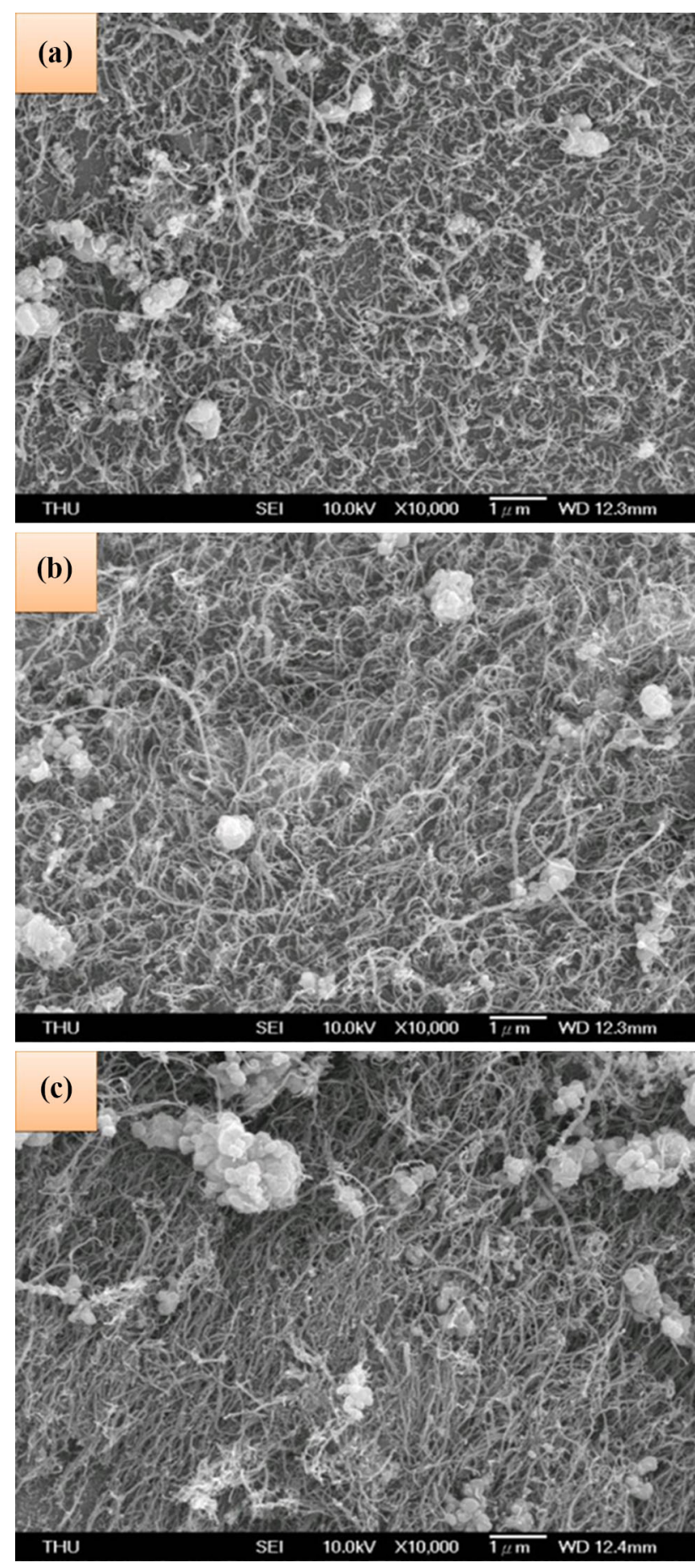

Fig. 3 SEM images of $\mathrm{SiO}_{2}$ particles with embedded MWCNTs synthesized at various $\mathrm{CH}_{4}$ flow rates: a $50 \mathrm{ml} / \mathrm{min}$, b $100 \mathrm{ml} / \mathrm{min}$, and c $300 \mathrm{ml} / \mathrm{min}$

coefficient, $R^{2}=0.99$ ). The fitting parameters are $r_{0}$ of $8.88 \mathrm{mg}_{\mathrm{CNT}} /\left(\mathrm{g}_{\text {subs }}-\mathrm{min}\right)$ and $\tau_{0}$ of $10.30 \mathrm{~min}$. These results imply deactivation of the catalysts after $10.30 \mathrm{~min}$. In other words, the reaction rate started to decrease after a reaction time of $10.30 \mathrm{~min}$. Figure 4 shows a TEM image of encapsulated iron at the tip of a MWCNT that originated

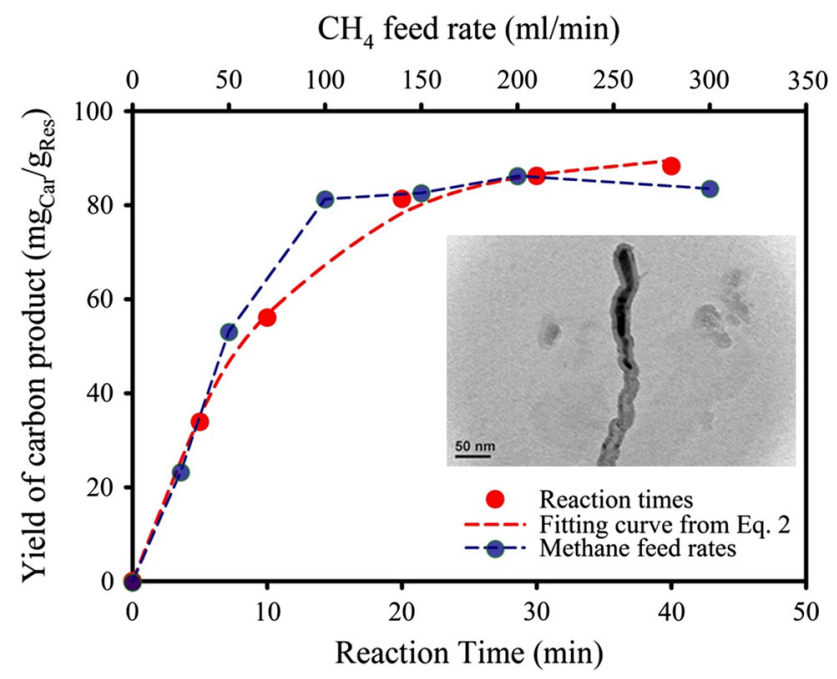

Fig. 4 Effect of $\mathrm{CH}_{4}$ flow rate and reaction time to the yield of MWCNTs [with TEM image (inset)]

from partial encapsulation of the catalyst by a carbon layer, which inhibited further reaction (Yamada et al. 2008). The MWCNT yield increased within a short reaction time, reaching a maximum at $20 \mathrm{~min}$. Therefore, the optimal conditions for obtaining the highest yield of MWCNTs are a $\mathrm{CH}_{4}$ flow rate of $100 \mathrm{ml} / \mathrm{min}$ and a reaction time of 20 min. MWCNTs synthesized under these conditions were then used in the adsorption study.

\section{Characterization of MWCNTs}

SEM and TEM images of the MWCNTs synthesized at a $\mathrm{CH}_{4}$ flow rate of $100 \mathrm{ml} / \mathrm{min}$ and a reaction time of $20 \mathrm{~min}$ are shown in Fig. 5. The MWCNTs are densely packed and vertically aligned on the $\mathrm{SiO}_{2}$ particles. This arrangement implies that the ferrocene catalyst has a significant influence on the MWCNT growth on the $\mathrm{SiO}_{2}$ microspheres in the FCCVD method. This effect is due to the decomposition nucleation of ferrocene, which assists the stacking growth of the MWCNTs (Lewis and Smith 1984). The dimensions of the MWCNTs were evaluated from the TEM images (Fig. 5b). The average outer and inner diameters were found to be 50 and $10 \mathrm{~nm}$, respectively. The estimated lattice spacing between the individual MWCNTs is $0.35 \mathrm{~nm}$, and the approximate number of walls is 57 . These characteristics are different from those reported by other researchers (Saleh et al. 2011; Zhang et al. 2008).

The as-synthesized $\mathrm{SiO}_{2}$ particles with embedded MWCNTs were characterized by Raman spectroscopy (spectrum is shown in Fig. 6). Intense labeled peaks at about 500, 220, and $129 \mathrm{~cm}^{-1}$ correspond to the $\mathrm{SiO}_{2}$ structure (Sun et al. 2015). An observable peak at $1340 \mathrm{~cm}^{-1}$ corresponds to disorder or defects in the carbon structure ( $\mathrm{D}$ band). The peak at $1570 \mathrm{~cm}^{-1}$ suggests the 

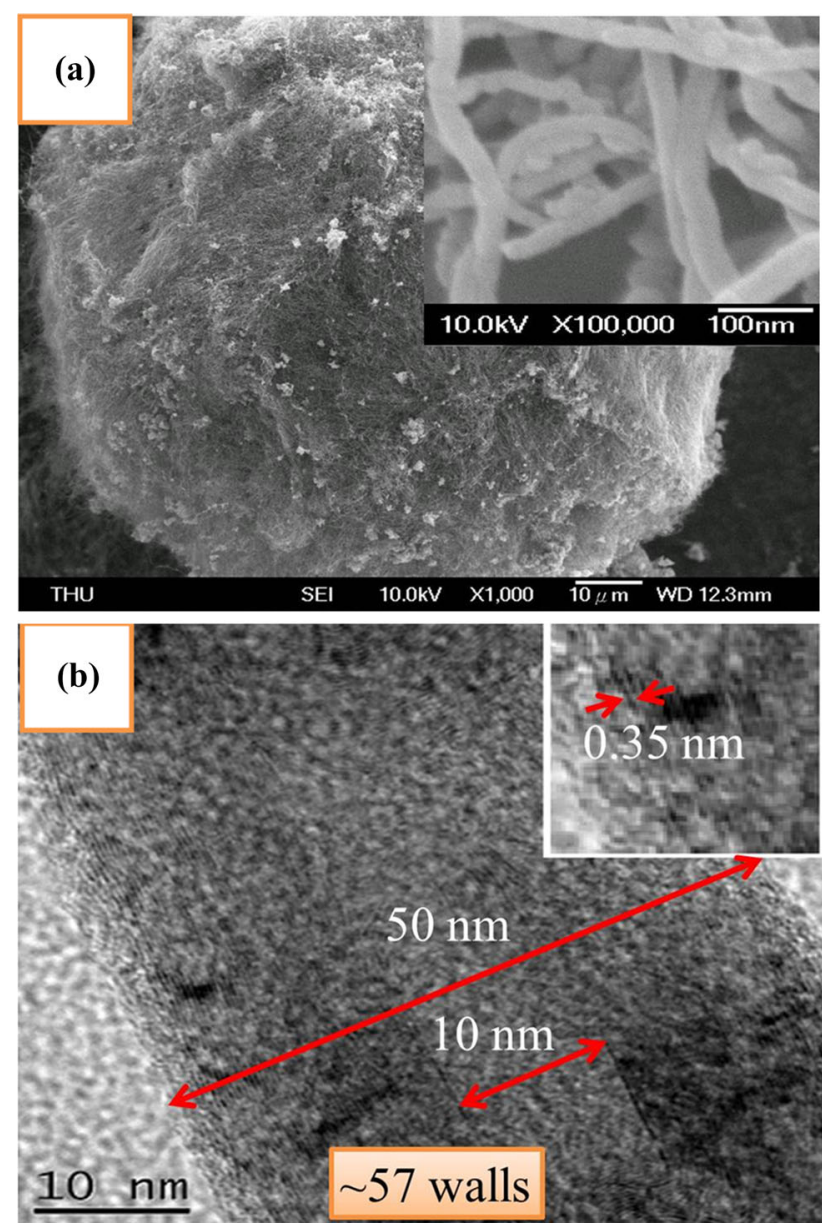

Fig. 5 a SEM and $\mathbf{b}$ TEM images of MWCNTs synthesized from the selected condition $\left(20 \mathrm{~min}\right.$ and $100 \mathrm{ml} / \mathrm{min}$ of $\left.\mathrm{CH}_{4}\right)$

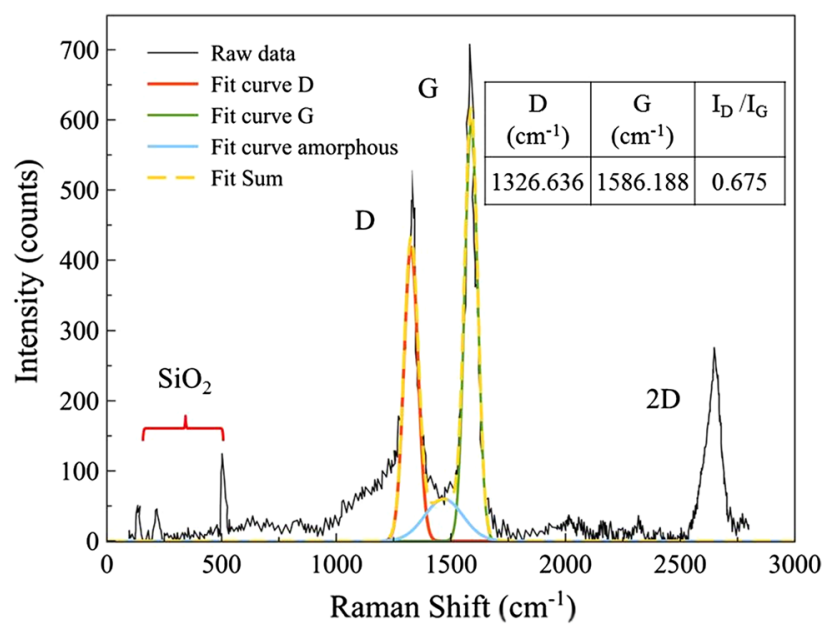

Fig. 6 Raman spectra of MWCNTs embedded in $\mathrm{SiO}_{2}$ particles

tangential mode of vibration of $\mathrm{C}-\mathrm{C}$ bonds, which manifests as the $\mathrm{G}$ band. The intensity ratio of the $\mathrm{D}$ band to the $\mathrm{G}$ band $\left(I_{\mathrm{D}} / I_{\mathrm{G}}\right)$ in the spectrum (0.77) indicates a large number of defects in the graphite wall, in accordance with

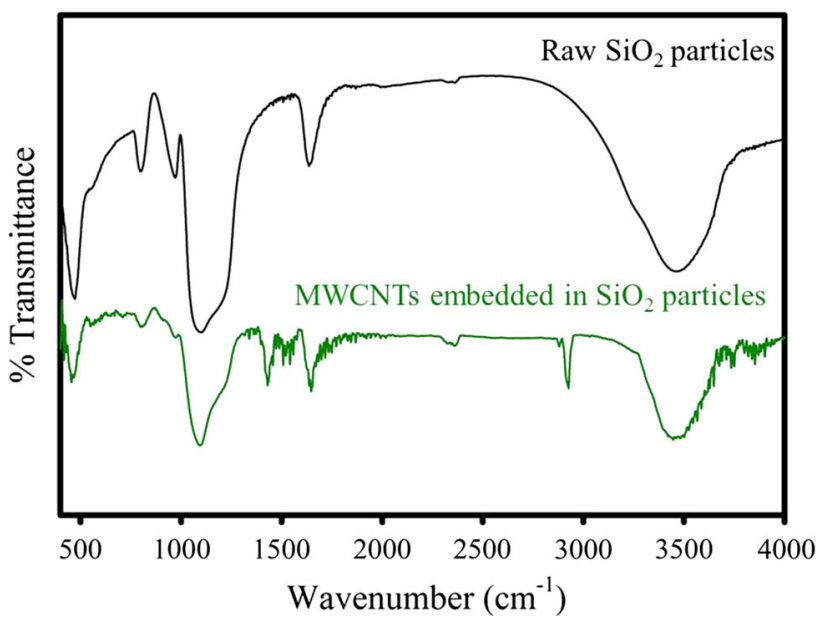

Fig. 7 FTIR spectra of raw $\mathrm{SiO}_{2}$ particles and MWCNTs embedded in $\mathrm{SiO}_{2}$ particles

the previous work of Jiang et al. (2009). The 2D band located at approximately $2700 \mathrm{~cm}^{-1}$ is a result of a double resonance process (Saleh 2015b, 2011).

FTIR spectroscopy was used to confirm the formation of MWCNTs embedded in the $\mathrm{SiO}_{2}$ particles. Figure 7 shows the FTIR spectra of raw $\mathrm{SiO}_{2}$ particles and MWCNTs embedded in the $\mathrm{SiO}_{2}$ particles. The band at $1090 \mathrm{~cm}^{-1}$ corresponds to the stretching vibration of $\mathrm{Si}-\mathrm{O}-\mathrm{Si}$. The longitudinal optical mode of the high-frequency $\mathrm{Si}-\mathrm{O}-\mathrm{Si}$ vibration is observed as the band at $1200 \mathrm{~cm}^{-1}$ (Saleh 2015a). The broad absorption band at around $3474 \mathrm{~cm}^{-1}$ corresponds to the $-\mathrm{OH}$ stretching vibration of the hydroxyl groups. Functional groups present in MWCNTs embedded in $\mathrm{SiO}_{2}$ particles can be verified from the $\mathrm{C}=\mathrm{C}$ stretching band $\left(1420 \mathrm{~cm}^{-1}\right)$, the $\mathrm{C}=\mathrm{O}$ stretching band $\left(1650 \mathrm{~cm}^{-1}\right)$, and the $\mathrm{C}-\mathrm{H}$ stretching vibration bands (2920 and $2880 \mathrm{~cm}^{-1}$ ) (Gupta et al. 2011a).

\section{Adsorption equilibrium}

In order to investigate the characteristics and the capacities of the $\mathrm{SiO}_{2}$ particles with embedded MWCNTs in the adsorption of gaseous CPCs, we conducted adsorption equilibrium studies. Figure 8a shows the equilibrium adsorption of CPCs vapors over MWCNTs within a range of extremely low concentrations. CPCs may be ranked according to adsorption capacities in decreasing order as DCP $>\mathrm{CP}>\mathrm{P}$. Adsorption data were evaluated by using three isotherm models, namely the Langmuir, Freundlich, and Redlich-Peterson (R-P) models. The Langmuir isotherm is derived by assuming that adsorption takes place on a homogenous surface without interactions between adsorbate molecules. In the adsorption process, a monolayer of gas molecules is strongly attached to the surface of the solid adsorbent. In general, the Langmuir isotherm and its linearized form are expressed as Eqs. 4 and 5, respectively. 
(a)

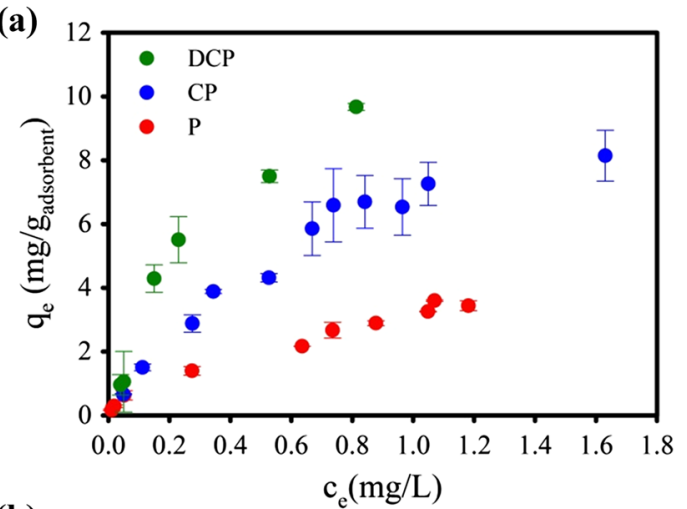

(b)

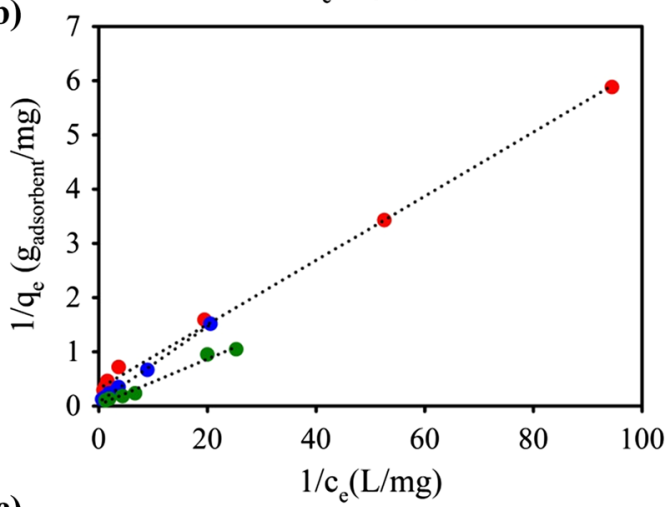

(c)

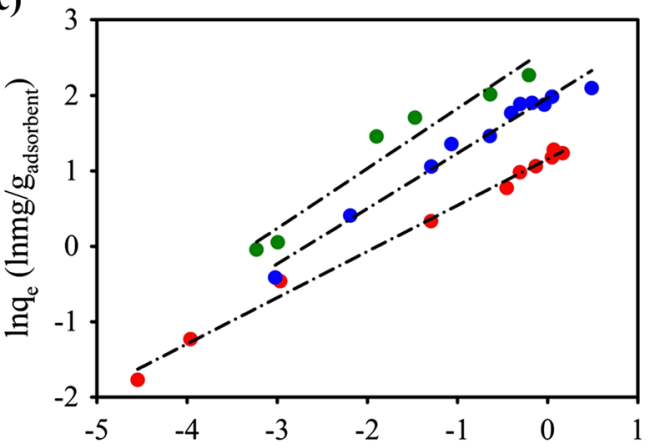

(d)

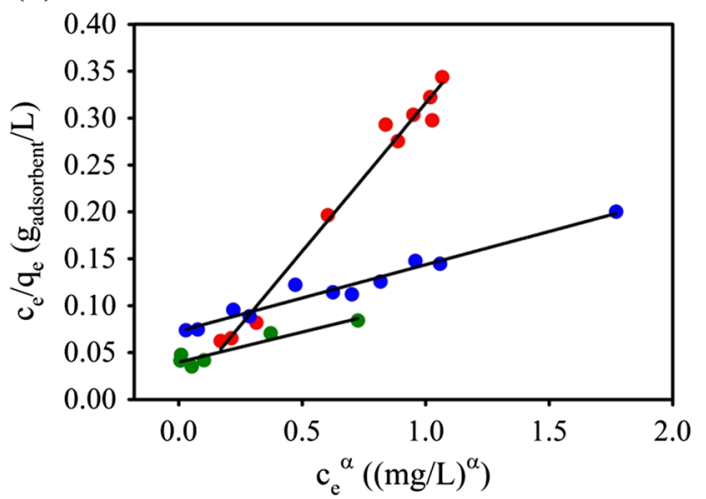

Fig. 8 a Equilibrium adsorption isotherm for $\mathrm{P}, \mathrm{CP}$, and DCP adsorbed onto $\mathrm{SiO}_{2}$ particles with embedded MWCNTs and adsorption fit with each model, b Langmuir model, $\mathbf{c}$ Freundlich model, and d R-P model where $\alpha=0.39,1.17$, and 1.55 for P, CP, and DCP, respectively $q_{\mathrm{e}}=\frac{q_{\mathrm{m}} b C_{\mathrm{e}}}{1+b C_{\mathrm{e}}}$

$\frac{1}{q_{\mathrm{e}}}=\frac{1}{b q_{\mathrm{m}}} \frac{1}{C_{\mathrm{e}}}+\frac{1}{q_{\mathrm{m}}}$

where $q_{\mathrm{e}}$ is the amount of adsorbed adsorbate per unit weight of the adsorbent at equilibrium $\left(\mathrm{mg} / \mathrm{g}_{\text {adsorbent }}\right), C_{\mathrm{e}}$ is the equilibrium concentration in the gaseous phase $(\mathrm{mg} / \mathrm{l})$, $b$ is a constant $(\mathrm{L} / \mathrm{mg})$, and $q_{\mathrm{m}}$ is the maximum adsorption capacity ( $\left.\mathrm{mg} / \mathrm{g}_{\text {adsorbent }}\right)$. The constants are determined from the slope and interception of the linear plot of $1 / q_{\mathrm{e}}$ versus $1 / C_{\mathrm{e}}$, as shown in Fig. $8 \mathrm{~b}$.

The Freundlich isotherm is based on the hypothesis of multilayer adsorption on heterogeneous adsorption sites. It can be expressed through the following formula:

$q_{\mathrm{e}}=K_{f} C_{\mathrm{e}}^{1 / n}$

The linear form of the Freundlich isotherm may be represented as

$\ln q_{\mathrm{e}}=\ln K_{f}+\frac{1}{n} \ln C_{\mathrm{e}}$

where $K_{f}$ is an indicator of adsorption capacity $\left(\mathrm{mg}^{1 / n} / \mathrm{mg}^{1 / n} \mathrm{~g}\right.$ ), and $n$ is the intensity of adsorption of the adsorbents. Both values are evaluated from the slope and interception of the plot of $\ln q_{\mathrm{e}}$ versus $\ln C_{\mathrm{e}}$, as shown in Fig. 8c.

A hybrid of the two-parameter Langmuir and Freundlich isotherms was also used in the study. Known as the R-P isotherm, it is expressed by three parameters, $q_{\mathrm{mon}}, \alpha$, and $b_{\mathrm{RP}}$, as shown in Eq. 8 (Wu et al. 2010):

$q_{\mathrm{e}}=\frac{q_{\mathrm{mon}} b_{\mathrm{RP}} C_{\mathrm{e}}}{1+b_{\mathrm{RP}} C_{\mathrm{e}}^{\alpha}}$

Rearrangement into its linear form gives

$\frac{C_{\mathrm{e}}}{q_{\mathrm{e}}}=\frac{1}{b_{\mathrm{RP}} q_{\mathrm{mon}}}+\left(\frac{1}{q_{\mathrm{mon}}}\right) C_{\mathrm{e}}^{\alpha}$

By trial and error determination of the $\alpha$ value, several plots of $C_{\mathrm{e}} / q_{\mathrm{e}}$ versus $C_{\mathrm{e}}^{\alpha}$ were constructed to optimize the fit. To determine the best $\alpha$ value, $R^{2}$ values of the linear plots were calculated for model comparisons. Figure $8 \mathrm{~d}$ shows the linearized R-P plots with the best $\alpha$ value for each CPC.

Table 1 summarizes the isotherm parameters with the best fit for all models with respect to the studied chemicals. The Langmuir model provides $R^{2}$ values in the range of 0.98-0.99, which are higher than those of Freundlich and R$\mathrm{P}$ models (around 0.89 and 0.99 , respectively). These coefficients indicate that the Langmuir model may be used to describe CPC adsorption. Generally, a $1 / n$ value of $<1$ indicates that the adsorption of adsorbate is favorable, and a 
Table 1 Isotherm parameters for CPCs fit on Langmuir, Freundlich, and R-P models

\begin{tabular}{|c|c|c|c|c|c|c|c|c|c|c|}
\hline \multirow[t]{2}{*}{ Chemical } & \multicolumn{3}{|c|}{ Langmuir isotherm $q_{\mathrm{e}}=\frac{q_{\mathrm{m}} b C_{\mathrm{e}}}{1+b C_{\mathrm{e}}}$} & \multicolumn{4}{|c|}{ Freundlich isotherm $q_{\mathrm{e}}=k C_{\mathrm{e}}^{1 / n}$} & \multicolumn{3}{|c|}{$\mathrm{R}-\mathrm{P}$ isotherm $q=\frac{b_{\mathrm{RP}} q_{\mathrm{mon}} C_{\mathrm{e}}}{1+b_{\mathrm{RP}} C_{\mathrm{e}}^{\alpha \alpha}}$} \\
\hline & $q_{\mathrm{m}}(\mathrm{mg} / \mathrm{g})$ & $b(\mathrm{~L} / \mathrm{mg})$ & $R^{2}$ & $1 / n$ & $k_{f}\left((\mathrm{mg} / \mathrm{g})(\mathrm{L} / \mathrm{mg})^{1 / n}\right)$ & $R^{2}$ & $\alpha$ & $b_{\mathrm{RP}}$ & $q_{\text {mon }}$ & $R^{2}$ \\
\hline $\mathrm{P}$ & 3.12 & 5.41 & 0.998 & 0.61 & 3.18 & 0.993 & 0.39 & $10,536.7$ & 3.16 & 0.982 \\
\hline $\mathrm{CP}$ & 13.83 & 1.04 & 0.998 & 0.73 & 7.19 & 0.975 & 1.17 & 0.97 & 14.1 & 0.960 \\
\hline DCP & 44.25 & 0.53 & 0.983 & 0.79 & 13.81 & 0.945 & 1.55 & 1.62 & 15.6 & 0.898 \\
\hline
\end{tabular}

Table 2 Comparative adsorption capacities of CPCs

\begin{tabular}{|c|c|c|c|}
\hline Material & Conditions phase/chemical probe $/ C_{\text {init }}$ & $\begin{array}{l}\text { Adsorption capacity } \\
(\mathrm{mg} / \mathrm{g})\end{array}$ & References \\
\hline MWCNTs & Aqueous phase $/$ phenol $/ C_{\text {init }}=5-50 \mathrm{mg} / \mathrm{l}$ & 64.6 & Dehghani et al. (2015) \\
\hline SWCNTs & Aqueous phase $/ 2$-chlorophenol $/ C_{\text {init }}=2 \mathrm{mg} / \mathrm{l}$ & 24.9 & Ding et al. (2015) \\
\hline $\begin{array}{l}\text { Surfactant-refluxed MWCNTs by } \\
\mathrm{HNO}_{3}\end{array}$ & $\begin{array}{l}\text { Aqueous phase/2,4-dichlorophenol/ } \\
\qquad C_{\text {init }}=1-1000 \mu \mathrm{g} / \mathrm{l}\end{array}$ & 24.15 & Kragulj et al. (2015) \\
\hline $\mathrm{Al}_{2} \mathrm{O}_{3}-\mathrm{CNTs}$ & Aqueous phase/4-chlorophenol $/ C_{\text {init }}=2 \mathrm{mg} / 1$ & 2.778 & $\begin{array}{l}\text { Tahermansouri et al. } \\
\text { (2015) }\end{array}$ \\
\hline \multirow[t]{2}{*}{ MWCNTs embedded in $\mathrm{SiO}_{2}$} & Gaseous phase $/$ phenol $/ C_{\text {init }}=0.04-2.0 \mathrm{mg} / \mathrm{l}$ & 3.12 & This work \\
\hline & 2-Chlorophenol $/ C_{\text {init }}=0.05-3.0 \mathrm{mg} / 1$ & 13.83 & \\
\hline
\end{tabular}

value $>1$ indicates that nonlinear adsorption on the heterogeneous surface (Hsu et al. 2014). All adsorptions fitted with the Freundlich isotherm have $1 / n$ values $<1$. This result implies favorable adsorption of each CPC on the MWCNTs. In Table 1, DCP shows an exceptionally high uptake, followed by those of CP and P. Maximum adsorption capacities $\left(q_{\max }\right)$ in Table 1 suggest that the compound with the highest uptake by the MWCNTs is DCP (44.25 mg/g $\mathrm{g}_{\text {sorbent }}$ ), followed by CP (13.83 mg/g $\left.\mathrm{g}_{\text {sorbent }}\right)$ and P (3.12 mg/g $\left./ \mathrm{g}_{\text {sorbent }}\right)$. Adsorption capacities of our material have been compared against those of other materials in Table 2 .

The greater the degree of chlorine substitution in the CPCs, the larger the amount of adsorbed CPCs onto the MWCNTs. The chlorine group is a considerably electronegative group that can draw electron density from the double bonds of the benzene ring. The electron density in the aromatic ring then decreases as the number of chlorine groups increases. On the other hand, the electron density in the aromatic ring of $\mathrm{CP}$ is lower than that of $\mathrm{P}$. Therefore, the affinity of DCP to $\pi$ electrons in MWCNTs surface is higher (Tóth et al. 2012).

Since the $R^{2}$ values of the Langmuir or Freundlich models are slightly different, it is unclear which model best represents these adsorption processes. Evaluation based on their adsorption energies was therefore carried out.

\section{Study of desorption energies}

To obtain the desorption energies, TGA-DTG was conducted to determine the weight loss as a function of heating rate. In general, desorption processes follow first-order kinetics with respect to the adsorbed species, as expressed in the equation $\mathrm{d} \theta / \mathrm{d} t=k_{\mathrm{d}} \theta$, where the parameter $\theta$ is the surface coverage and $k_{\mathrm{d}}$ is the desorption rate constant. According to the Arrhenius equation, $k_{\mathrm{d}}=A \exp \left(E_{\mathrm{d}} / \mathrm{RT}\right)$, $k_{\mathrm{d}}$ is a function of temperature. When the temperature profile is a linear function of time and heating rate, the firstorder equation may be integrated as described in Eq. 10:

$$
\int_{\Theta_{0}}^{\Theta_{t}}-\frac{\mathrm{d} \Theta}{\Theta}=\frac{A}{B} \int_{T_{0}}^{T_{t}} \exp \left(-\frac{E_{\mathrm{d}}}{\mathrm{RT}}\right) \mathrm{d} T
$$

where $A$ is the pre-exponential factor, $B$ is the heating rate $\left({ }^{\circ} \mathrm{C} /\right.$ $\min$ ), and $\theta_{O}$ and $\theta_{t}$ are the surface coverage at time $t=0$ and $t$, respectively. $R$ is the gas constant, $T$ is the temperature $(K)$, and $E_{\mathrm{d}}$ is the activation energy for desorption. The maximum temperature $\left(T_{\mathrm{m}}\right)$ was obtained by plotting the derivative of the thermogram against the temperature program of $\mathrm{SiO}_{2}$ particles with embedded MWCNTs for each CPC. Equation 10 may be integrated and expressed as a linear function in Eq. 11. The desorption energy was obtained from the slope of the plot of $2 \ln T_{\mathrm{m}}-\ln B$ versus $1000 / T_{\mathrm{m}}$.

$2 \ln T_{\mathrm{m}}-\ln B=\frac{E_{\mathrm{d}}}{R T_{\mathrm{m}}}+\frac{E_{\mathrm{d}}}{A R}$

Figure $9 \mathrm{a}-\mathrm{c}$ shows desorption profiles of each $\mathrm{CPC}$ at different heating rates $\left(1,3,5\right.$, and $\left.7{ }^{\circ} \mathrm{C} / \mathrm{min}\right)$. Higher heating rates delayed the desorption peaks for all absorbed CPCs. $T_{\mathrm{m}}$ values obtained were plotted against the heating rates, as shown in Fig. 9d. The results clearly indicate that 

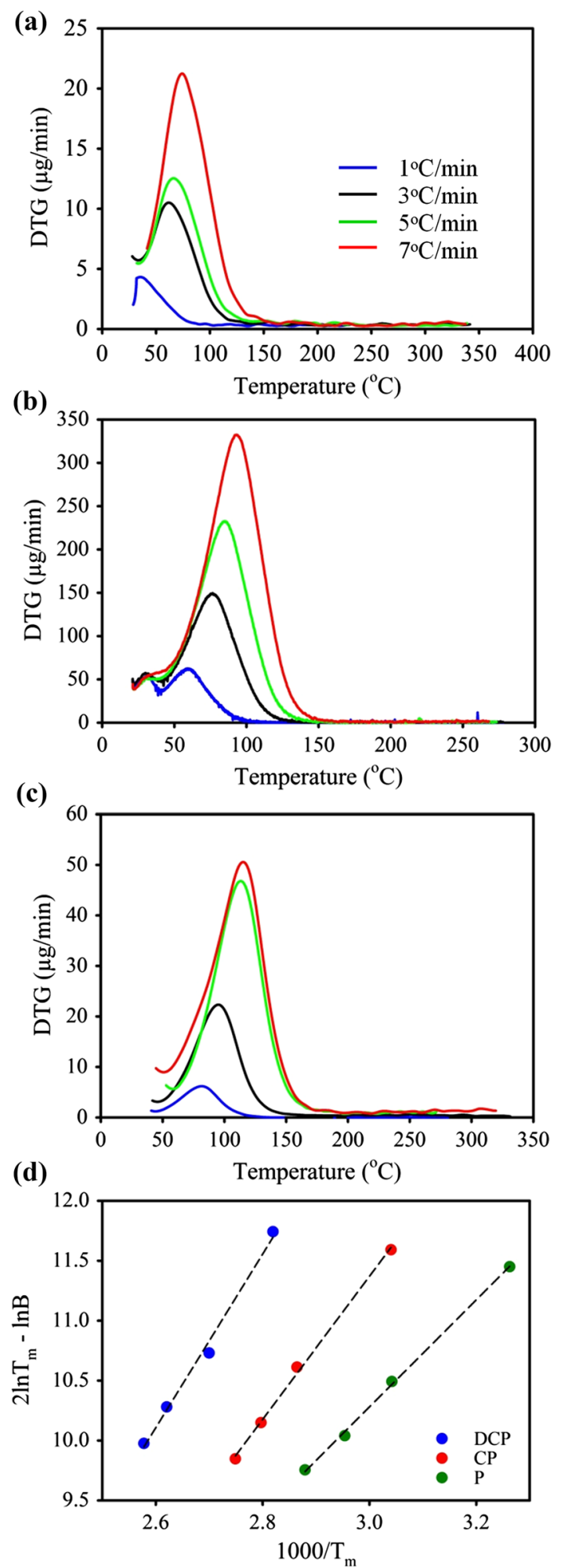

Fig. 9 Temperature-programmed desorption profiles for a $\mathrm{P}, \mathbf{b} \mathrm{CP}$, c DCP, and d plots of $2 \ln T_{\mathrm{m}}-\ln B$ versus $1000 / T_{\mathrm{m}}$

the DCP profile exhibits the steepest slope, followed by those of CP and P. Calculated $E_{\mathrm{d}}$ values of the CPCs in the study are summarized in Table 3 . Theoretically, adsorption
Table 3 Desorption energy $\left(E_{\mathrm{d}}\right)$ for CPCs onto MWCNTs

\begin{tabular}{ll}
\hline & Desorption energy $(\mathrm{kJ} / \mathrm{mol})$ \\
\hline $\mathrm{P}$ & 37.2 \\
$\mathrm{CP}$ & 49.6 \\
$\mathrm{DCP}$ & 62.2 \\
\hline
\end{tabular}

behaviors may be classified as physisorption or chemisorption on the basis of $E_{\mathrm{d}}$. An adsorption process with an $E_{\mathrm{d}}$ of $<40 \mathrm{~kJ} / \mathrm{mol}$ is generally categorized as physisorption; otherwise, it is categorized as chemisorption (Guo et al. 2014).

According to Table 3, the adsorption behaviors of CP and DCP are predominantly chemisorption, that is, these adsorbates adsorb as a monolayer. On the other hand, $\mathrm{P}$ adsorption has a low $E_{\mathrm{d}}$ and thus corresponds to physisorption behavior. This result indicates that attraction between sorbate molecules is stronger than that between the sorbate and sorbent, and that the sorbate adsorbs as multilayers on the sorbent surface. Hence, a physisorption interaction can appropriately describe the adsorption of $\mathrm{P}$ on MWCNTs.

Since the enthalpy of vaporization of $\mathrm{P}$ is $43.8 \mathrm{~kJ} / \mathrm{mol}$, which is higher than its $E_{\mathrm{d}}(37.2 \mathrm{~kJ} / \mathrm{mol})$, the energy of bonding between the adsorbate molecules is stronger than that of bonding between the adsorbate and the adsorbent. The adsorption of $\mathrm{P}$ onto MWCNTs corresponds to multilayer adsorption, as explained by the Freundlich model. In the cases of CP and DCP, the heats of vaporization are 45.2 and $60.8 \mathrm{~kJ} / \mathrm{mol}$, respectively (Chickos and Acree 2003). These are slightly lower than the corresponding $E_{\mathrm{d}}$ values (49.6 and $62.2 \mathrm{~kJ} / \mathrm{mol}$, respectively). Their energies of bonding with the adsorbent seem to be stronger than those with the adsorbate molecules. Thus, the adsorption behaviors of $\mathrm{CP}$ and DCP on the adsorbent may be described as monolayer formation via a chemisorption process. For these molecules, the Langmuir isotherm may be used to describe adsorption behaviors.

\section{Conclusion}

MWCNTs were synthesized through the FCCVD technique at $\mathrm{H}_{2}$ and Ar flow rates of 300 and $200 \mathrm{ml} / \mathrm{min}$, respectively. The parameters studied for optimization were the $\mathrm{CH}_{4}$ flow rate $(25-300 \mathrm{ml} / \mathrm{min})$ and the reaction time (5-40 min). Optimal conditions for obtaining a high yield of MWCNTs were 20-min reaction time and $100 \mathrm{ml} / \mathrm{min}$ $\mathrm{CH}_{4}$ flow rate. The obtained MWCNTs were then studied for their adsorption of the phenolic compounds $\mathrm{P}, \mathrm{CP}$, and DCP. Adsorption of the gas phase within a concentration range of 1-500 ppm was conducted. CPCs may be ranked 
according to $E_{\mathrm{d}}$ values in the descending order DCP $(62.2 \mathrm{~kJ} / \mathrm{mol})>\mathrm{CP} \quad(49.6 \mathrm{~kJ} / \mathrm{mol})>\mathrm{P} \quad(37.2 \mathrm{~kJ} / \mathrm{mol})$. Adsorption of phenolic compounds onto MWCNTs followed a physisorption process, whereas adsorption of $\mathrm{CP}$ and DCP followed a chemisorption process. Experimental data fit more closely the Langmuir isotherm than they fit the Freundlich or the R-P isotherm. $q_{\max }$ values for P, CP, and DCP on MWCNTs are 3.12, 13.83, and $44.25 \mathrm{mg} / \mathrm{g}$, respectively.

Acknowledgments This study was financially supported by the Ministry of Science and Technology (MoST) in Taiwan, through project grant 102-2221-E-029-003-MY3. S. Tulaphol is supported by the Royal Golden Jubilee program contract Grant PHD/01802553, Faculty of Engineering, Thammasat University (Thailand).

\section{References}

Agnihotri S, Rood MJ, Rostam-Abadi M (2005) Adsorption equilibrium of organic vapors on single-walled carbon nanotubes. Carbon 43:2379-2388

Ali I (2012) New generation adsorbents for water treatment. Chem Rev 112(10):5073-5091

Bunsan S, Chen W-Y, Chen H-W, Chuang YH, Grisdanurak N (2013) Modeling the dioxin emission of a municipal solid waste incinerator using neural networks. Chemosphere 92:258-264

Chen C, Hu J, Shao D, Li J, Wang X (2009) Adsorption behavior of multiwall carbon nanotube/iron oxide magnetic composites for $\mathrm{Ni}(\mathrm{II})$ and $\mathrm{Sr}(\mathrm{II})$. J Hazard Mater 164:923-928

Chickos JS, Acree WE (2003) Enthalpies of vaporization of organic and organometallic compounds, 1880-2002. J Phys Chem Ref Data 32:519-878

Crespo D, Yang RT (2006) Adsorption of organic vapors on singlewalled carbon nanotubes. Ind Eng Chem Res 45:5524-5530

Dehghani MH, Mostofi M, Alimohammadi M, McKay G, Yetilmezsoy K, Albadarin AB, Heibati B, AlGhouti M, Mubarak NM, Sahu JH (2015) High-performance removal of toxic phenol by single-walled and multi-walled carbon nanotubes: kinetics, adsorption, mechanism and optimization studies. J Ind Eng Chem 35:63-74

Ding H, Li X, Wang J, Zhang X, Chen C (2015) Adsorption of chlorophenols from aqueous solutions by pristine and surface functionalized single-walled carbon nanotubes. J Environ Sci. doi:10.1016/j.jes.2015.09.004

Guo Y, Li Y, Wang J, Zhu T, Ye M (2014) Effects of activated carbon properties on chlorobenzene adsorption and adsorption product analysis. Chem Eng J 236:506-512

Gupta VK, Agarwal S, Saleh TA (2011a) Synthesis and characterization of alumina-coated carbon nanotubes and their application for lead removal. J Hazard Mater 185:17-23

Gupta VK, Gupta B, Rastogi A, Agarwal S, Nayak A (2011b) Pesticides removal from waste water by activated carbon prepared from waste rubber tire. Water Res 45:4047-4055

Gupta VK, Ali I, Saleh TA, Nayak A, Agarwal S (2012) Chemical treatment technologies for waste-water recycling-an overview. RSC Adv 2:6380-6388

Gupta VK, Kumar R, Nayak A, Saleh TA, Barakat MA (2013) Adsorptive removal of dyes from aqueous solution onto carbon nanotubes: a review. Adv Colloid Interface Sci 193-194:24-34

He D, Bozlar M, Genestoux M, Bai J (2010) Diameter- and lengthdependent self-organizations of multi-walled carbon nanotubes on spherical alumina microparticles. Carbon 48:1159-1170
Hsu S-H, Huang C-S, Chung T-W, Gao S (2014) Adsorption of chlorinated volatile organic compounds using activated carbon made from Jatropha curcas seeds. J Taiwan Inst Chem Eng 45:2526-2530

Jiang Z, Yu X, Z-j J, Meng Y, Shi Y (2009) Synthesis of monodispersed $\mathrm{Pt}$ nanoparticles on plasma processed carbon nanotubes for methanol electro-oxidation reaction. J Mater Chem 19:6720-6726

Kragulj M, Tričković J, Kukovecz Á, Jović B, Molnar J, Rončević S, Kónya Z, Dalmacija B (2015) Adsorption of chlorinated phenols on multiwalled carbon nanotubes. RSC Adv 5:24920-24929

Lewis KE, Smith GP (1984) Bond dissociation energies in ferrocene. J Am Chem Soc 106:4650-4651

Lin D, Xing B (2008) Adsorption of phenolic compounds by carbon nanotubes: role of aromaticity and substitution of hydroxyl groups. Environ Sci Technol 42:7254-7259

Long RQ, Yang RT (2001) Carbon nanotubes as superior sorbent for dioxin removal. J Am Chem Soc 123:2058-2059

Salam MA, Mokhtar M, Basahel SN, Al-Thabaiti S, Obaid AY (2010) Removal of chlorophenol from aqueous solutions by multiwalled carbon nanotubes: kinetic and thermodynamic studies. J Alloys Compd 500:87-92

Saleh TA (2011) The influence of treatment temperature on the acidity of MWCNT oxidized by $\mathrm{HNO}_{3}$ or a mixture of $\mathrm{HNO}_{3} /$ $\mathrm{H}_{2} \mathrm{SO}_{4}$. Appl Surf Sci 257:7746-7751

Saleh TA (2015a) Isotherm, kinetic, and thermodynamic studies on $\mathrm{Hg}(\mathrm{II})$ adsorption from aqueous solution by silica-multiwall carbon nanotubes. Environ Sci Pollut Res 22:16721-16731

Saleh TA (2015b) Nanocomposite of carbon nanotubes/silica nanoparticles and their use for adsorption of $\mathrm{Pb}(\mathrm{II})$ : from surface properties to sorption mechanism. Desalin Water Treat. doi:10. 1080/19443994.2015.1036784

Saleh TA, Agarwal S, Gupta VK (2011) Synthesis of MWCNT/MnO and their application for simultaneous oxidation of arsenite and sorption of arsenate. Appl Catal B Environ 106:46-53

Shih YH, Li MS (2008) Adsorption of selected volatile organic vapors on multiwall carbon nanotubes. J Hazard Mater $154: 21-28$

Sun Y, Zhang Z, Liu L, Wang X (2015) FTIR, Raman and NMR investigation of $\mathrm{CaO}-\mathrm{SiO}_{2}-\mathrm{P}_{2} \mathrm{O}_{5}$ and $\mathrm{CaO}-\mathrm{SiO}_{2}-\mathrm{TiO}_{2}-\mathrm{P}_{2} \mathrm{O}_{5}$ glasses. J Non-Cryst Solids 420:26-33

Tahermansouri H, Dehghan Z, Kiani F (2015) Phenol adsorption from aqueous solutions by functionalized multiwalled carbon nanotubes with a pyrazoline derivative in the presence of ultrasound. RSC Adv 5:44263-44273

Tóth A, Törőcsik A, Tombácz E, László K (2012) Competitive adsorption of phenol and 3-chlorophenol on purified MWCNTs. J Colloid Interface Sci 387:244-249

US Environmental Protection Agency (2000) Priority PBTs: dioxins and furans fact sheet. Office Prevention and Toxics, Washington, DC. www.epa.gov/epawaste/hamin/mimimize/factshts/dioxfura. pd

Wu F-C, Liu B-L, Wu K-T, Tseng R-L (2010) A new linear form analysis of Redlich-Peterson isotherm equation for the adsorptions of dyes. Chem Eng J 162:21-27

Yamada T, Maigne A, Yudasaka M, Mizuno K, Futaba DN, Yumura M, Iijima S, Hata K (2008) Revealing the secret of waterassisted carbon nanotube synthesis by microscopic observation of the interaction of water on the catalysts. Nano Lett $8: 4288-4292$

Yu H, Li Z, Zhang C, Peng F, Wang H (2007) growth of aligned carbon nanotubes on large scale by methane decomposition with deactivation inhibitor. J Nat Gas Chem 16:382-388

Zhang Q, Huang J-Q, Zhao M-Q, Qian W-Z, Wang Y, Wei F (2008) Radial growth of vertically aligned carbon nanotube arrays from ethylene on ceramic spheres. Carbon 46:1152-1158 